\title{
ON THE INTEGRATIVE SYNAPTIC POTENTIALS OF ONCHIDIUM NERVE CELL
}

\author{
Kiyoshi Kusano and Susumu Hagiwara* \\ Department of Physiology, Tokyo Medical and Dental University, Tokyo
}

The ganglion systems of a certain marine mollusc, Onchidium verruculatum contain a number of giant nerve cells (Hagiwara \& SaITo, 1959). The cell receives presynaptic fibres from the roots of the ganglia and they form a number of excitatory and inhibitory synapses. An impulse of a single excitatory presynaptic fibre was usually too small to set up a spike potential of the cell and the spatial and temporal summation was necessary to initiate spikes. In most cases one to one correspondence was not found between the presynaptic impulse and the postsynaptic spike even when the spike potential was present in the cell. The present paper was planned to investigate these integrative synapses especially the spatial and temporal summation of the presynaptic effect. The results on the inhibitory synapse was reported in a separate paper (HAGIWARA \& Kusano, 1960).

\section{METHODS}

For the experiments isolated supra- and suboesophageal ganglia with roots of a marine pulmonate mollusc, Onchidium verruculatum were used. The general arrangements of the experiments were similar to those described in the previous paper (Hagrwara \& Kusano, 1960). Glass capillary tubes of tip diameter less than $0.5 \mu$, filled with $3 \mathrm{M}-\mathrm{KCl}$ solution, were used for recording the membrane potential change as well as for polarizing the cell membrane. The amplifier systems were similar to those employed in the previous work (Hagrwara \& SaIto, 1959). The artificial sea water had the following composition (YАмамото, 1948) $\mathrm{NaCl}, 465 \mathrm{~mm}$; $\mathrm{KCl}, 9.3 \mathrm{~mm}$; $\mathrm{CaCl}_{2}, 10.8 \mathrm{~mm} ; \mathrm{MgCl}_{2}, 48.3 \mathrm{mM} ; \mathrm{NaHCO}_{3}, 5.9 \mathrm{~mm}$. All the experiments were carried out at room temperature $\left(20-23^{\circ}\right)$.

\section{RESULTS}

I. Spacial and temporal summation of e.p.s.p.; The stimulation of the most roots produced an excitatory postsynaptic potential (e.p.s.p.), the amplitude of which was graded with the increase of stimulus intensity. When the amplitude reached a certain value it set up a spike. Such a gradation was more markedly

Received for publication September 16, 1960.

$*$ 草野 皓, 萩原生長 
demonstrated when the spike initiation was prevented by anodal polarization as shown by record A of FIG. 1 obtained at $88 \mathrm{mV}$ hyperpolarization. Since the stimulation of any several different roots produced such graded synaptic potentials in each cell, the cell must receive a number of different excitatory presynaptic fibres. Sometimes spontaneous discharges of e.p.s.p.'s were observed. The amplitudes of such spontaneous potentials were usually very small and they were subthreshold for the spike when the frequency of discharge was small. Therefore a single impulse in a presynaptic axon seemed to produce only a small synaptic potential and spatial summation was necessary for the single presynaptic stimulation to give rise of a postsynaptic spike. Since the stimulation of a certain root usually produced similar synaptic potentials in several different nerve cells, it is likely that a single presynaptic fibre branches and innervates many nerve cells.

The synaptic potentials obtained in a membrane hyperpolarized by $55 \mathrm{mV}$ with various frequencies of stimulation are shown in FIG. $1 \mathrm{~B}$ and $\mathrm{C}$. Records $\mathrm{B}$ and $\mathrm{C}$ were obtained in the same cell on stimulating the same root but the stimulus intensity was higher in $\mathrm{C}$. In both cases summation of the synaptic potentials became marked as the frequency of stimulus was increased. The potential change reached a final amplitude which increased with frequency up to a certain maximum. Increase of frequency above this limit did not produce any further increase in the potential change, but increased the rate with which it reached maximum amplitude. Under normal conditions a larger value of the maximum amplitude was usually obtained when the amplitude of single synaptic potential was larger. The maximum amplitude reached during repetitive stimulation was 3 to 5 times that observed with a single stimulus. These results show that the temporal summation was also important for the synaptic potential to produce a postsynaptic spike.

Even when a few presynaptic fibres were stimulated synchronously the postsynaptic spike usually did not follow each stimulus as shown by records A of
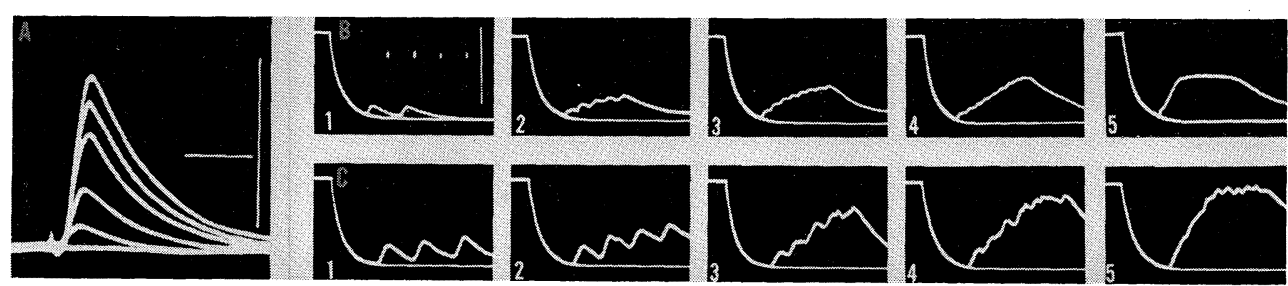

FIG. 1. Excitatory postsynaptic potentials obtained at hyperpolarized membranes. A, Effect of stimulus intensity applied to the root. Record was obtained at $88 \mathrm{mV}$ hyperpolarization. B and C, Effect of frequency of presynaptic stimuli. $\mathbf{B}$ and $\mathbf{C}$ were obtained by stimulating the same root but the intensity of stimulus was lower in B than in C. Voltage calibration, $50 \mathrm{mV}$; time, $50 \mathrm{msec}$. 

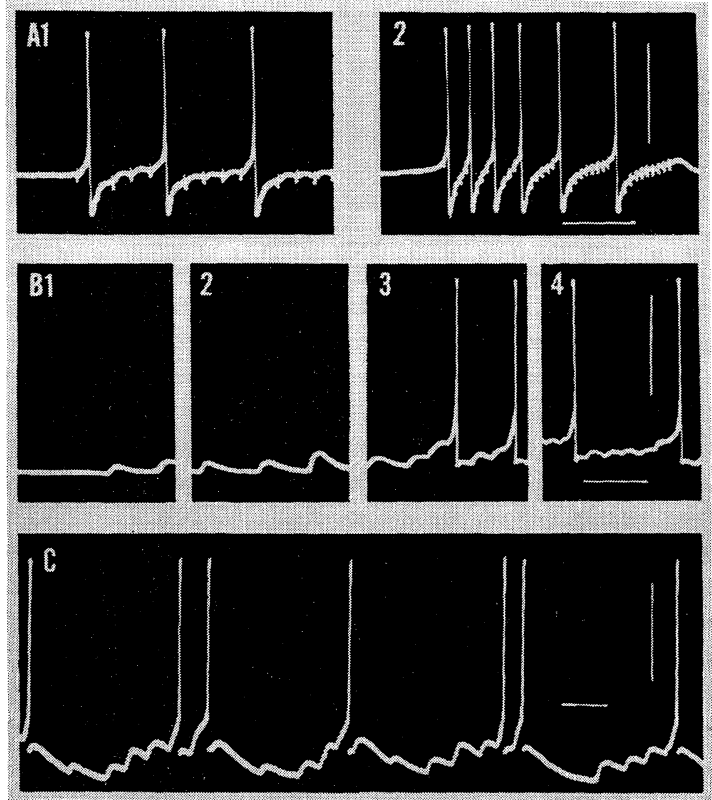

FIG. 2. A, Repetitive presynaptic stimulation at the resting membrane. Stimulus frequency was lower in 1 than in 2 but the stimulus intensity was the same. B and C, Spontaneous discharges of e.p.s.p's. The frequency of discharge was gradually increasing in $\mathbf{B}$ and it varied rhythmically in $\mathbf{C}$. Voltage calibration, $50 \mathrm{mV}$; time, $1 \mathrm{sec}$.

FIG. 2. A series of postsynaptic spikes was initiated by the depolarization when the amplitude was sufficient. As the frequency of stimulus increased the frequency of postsynaptic spike became higher but direct correspondence was not seen between each presynaptic stimulus and the spike. This pattern of spike initiation was very similar to that observed with polarization by an outward constant current. A series of records in FIG. $2 \mathrm{~B}$ was taken while the frequency of spontaneous synaptic potentials was increasing. The depolarization developed at the cell membrane increased with frequency and spike potentials were initiated when it exceeded the firing level. Sometimes bursts of synaptic potentials appeared with a certain rhythm as shown by record $\mathrm{C}$ of the same figure. All of these results show the integrative function of the present systems.

II. Effects of $\mathrm{Ca}$ and $\mathrm{Mg}$ on e.p.s.p.; The amplitude of synaptic potential was greatly influenced by the concentration of $\mathrm{Ca}$ and $\mathrm{Mg}$ in the solution surrounding the preparation. When the external normal sea water $(10.8 \mathrm{mM}-\mathrm{Ca}$ and $48.3 \mathrm{~mm}-\mathrm{Mg}$ ) was replaced by a modified sea water which contained excess $\mathrm{Ca}(60 \mathrm{~mm})$ the amplitude of the synaptic potential was markedly increased (Record B-1 of Fig. 3). In contrast to this a marked decrease of amplitude was observed with the sea water containing excess $\mathrm{Mg}$ (144 mM) (Record C-1 of 


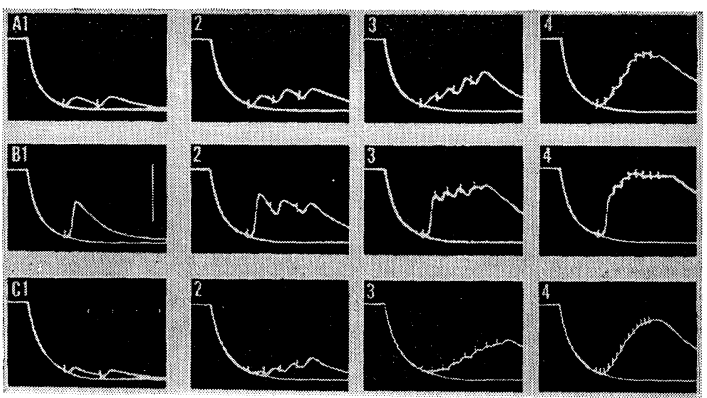

FIG. 3. e.p.s.p.'s obtained in normal medium $(10.8 \mathrm{~mm}-\mathrm{Ca}$ and $48.3 \mathrm{mM}$ $\mathrm{Mg}, \mathrm{A})$, in Ca-rich medium (60 mM-Ca, B) and in Mg-rich medium (144 mM$\mathrm{Mg}, \mathrm{C}$ ). The records also show the effect of stimulus frequency. All the records were obtained with the same cell by stimulating the same root. Stimulus intensity was unchanged throughout. Voltage calibration $50 \mathrm{mV}$; time, $50 \mathrm{msec}$.

FIG. 3). Those changes were completely reversed when the preparation was restored to normal sea water. The effects were not on the stimulated region of the axons because the stimulated portions of the roots were immersed in normal sea water throughout the experiment.

As described before the amplitude of the synaptic potential could be increased up to a certain maximum by the repetitive presynaptic stimulation in the normal medium. Although the amplitude of the single synaptic potential was small in the excess $\mathrm{Mg}$, it was greatly increased by the repetitive stimulation. On the other hand in the excess $\mathrm{Ca}$ the successive stimulation caused only a small additional increase of the amplitude (FIG. 3). Thus the maximum amplitude of synaptic potentials reached by repetitive stimulation was almost unchanged by the increase of external $\mathrm{Ca}$ or $\mathrm{Mg}$ concentration even though the amplitude of the single synaptic potential was greatly modified. The results, therefore, indicate that in the Ca-rich medium the conductance of the synaptic membrane is close to the maximum value for a single presynaptic impulse and that it is a certain fraction in the normal or in the Mg-rich medium. These results show that the increase of the amplitude of the synaptic potential produced by repetitive presynaptic stimulation is not due to a simple temporal summation but to the increase of the active area of the synaptic membrane innervated by each presynaptic fibre.

III. Antidromic spike and e.p.s.p.; Besides spike potentials initiated by e.p.s.p.'s stimulation of the root sometimes produced an antidromic spike in the cell. In such a case an impulse was always recorded from the root when a spike potential was produced in the cell by transmembrane stimulation (Record A of FIG. 4). When the antidromic stimulus was applied during anodal polarization of the cell membrane it produced a small all or none potential change which did not give rise to a spike. As reported previously (Hagiwara \& SaIto, 1959) this 
represents an electrotonic potential in the soma membrane produced by the action current of the axon some distance from the soma. Although the shape of such a potential was very like that of the synaptic potential, the two potentials were distinguishable by anodal polarization of higher intensity.

When the anodal current was increased the abortive potential usually disappeared. Sometimes the potential showed a steplike decrease with increase of hyperpolarization (Record B of FIG. 4). This phenomenon indicates that the antidromic impulse terminated in a more distal region of the axon because of spread of the hyperpolarization from the soma. The steplike decrease indicates that this distance increased in a steplike-fashion. However the effect was different on the e.p.s.p. Records D show e.p.s.p. obtained during anodal polarizations of various intensities. With anodal polarization the peak level of the synaptic potential was lowered but the amplitude measured from the altered membrane potential level increased linearly with increase of hyperpolarization. The linear relation indicated that the amplitude of the synaptic potential should become zero around zero membrane potential. This did not depend on the amplitude of the synaptic potential obtained at the resting membrane potential level. 'These results are similar to those obtained for other excitatory synapses (FATT \& KATZ, 1951; Eccles, 1957; Hagiwara \& TASAKI, 1958). When stimulation of the root produced the synaptic potential together with the antidromic spike, the increasing hyperpolarization increased the amplitude of the synaptic potential while it abolished the potential change due to the antidromic stimulation. Therefore at large hyperpolarizations, a pure synaptic potential was recorded as shown by record C of Fig. 4.

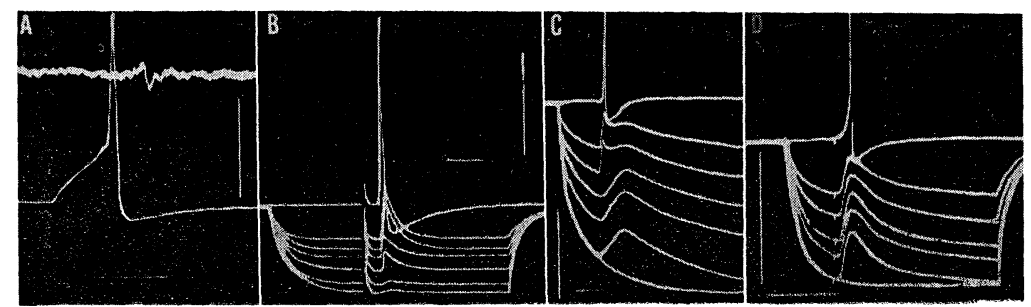

FIG. 4. A, Spike potential produced by intracellular stimulation of the cell in the lower trace and the impulse of the axon recorded with a pair of wire electrodes placed on the root. B, Effect of anodal polarization on the antidromic spike potential. C, Effect of anodal polarization when the root stimulation produced an antidromic spike and e.p.s.p. D, Effect of anodal polarization of e.p.s.p. Voltage calibration $50 \mathrm{mV}$; time $50 \mathrm{msec}$.

\section{DISCUSSION}

In some synapses such as the endplate of the vertebrate, squid giant synapse an impulse of a single presynaptic fibre was usually sufficient to produce a postsynaptic spike. However in the Onchidium giant nerve cell system it is generally 
insufficient. By spatial and temporal summation the presynaptic impulse depolarizes the cell membrane, which leads to the initiation of postsynaptic spikes. The frequency of the postsynaptic spike discharge is determined by the sum of presynaptic impulses arriving at the neurone. Similar properties have been observed in Aplysia and snail which are closely related to Onchidium (TAUC, 1958). The results on the effects of $\mathrm{Ca}$ and $\mathrm{Mg}$ indicate that a single impulse of presynaptic fibre does not activate all the synaptic membrane innervated by the fibre and the active area increases during the successive arrival of presynaptic impulses. Similar phenomena have been observed in the endplate potential of the amphibian muscle by del Castillo \& Engbaek (1954) and del Castillo \& STARK (1952).

\section{SUMMARY}

1. Excitatory postsynaptic potentials (e.p.s.p.'s) of the giant nerve cell system of Onchidium verruculatum were investigated by intracellular electrode technique. 2. An impulse of a single presynaptic fibre was usually too small to initiate a postsynaptic spike and spacial and temporal summation was necessary to produce the postsynaptic spike.

3. The increase of calcium or magnesium concentration in the external medium increased or decreased the amplitude of the e.p.s.p. respectively but the maximum amplitude of the synaptic potential reached by repetitive presynaptic stimulation was practically unchanged.

4. From the above results the temporal facilitation is produced by increasing the active area of the synaptic membrane innervated by a single presynaptic fibre.

The authors wish to express their gratitude to Dr. N. SAITo for his assistance throughout the experiment and to Dr. C. EDwards for his valuable discussion. The present work was supported by grant from the Rockefeller Foundation and the Ministry of Education in Japan.

\section{REFERENCES}

1) Del Castillo, J. And Stark, L. The effect of calcium ions on the motor end-plate potentials. J. Physiol., 116: 507-515, 1952.

2) Del Castillo, J. and Engbaek, L. The nature of the neuromuscular block produced by magnesium. J. Physiol., 124: 370-384, 1954.

3) Eccles, J. C. The Physiology of Nerve Cells. Johns Hopkins Press, 1957.

4) Fatt, P. AND Katz, B. An analysis of the end-plate potential recorded with an intracellular electrode. J. Physiol., 115: 328-370, 1951.

5) Hagiwara, S. ANd Sarto, N. Voltage-current relations in nerve cell membrane of Onchidium verruculatum. J. Physiol., 148: 161-170, 1959.

6) Hagiwara, S. and Kusano, K. Synaptic inhibition in giant nerve cell of Onchidium verruculatum. J. Neurophysiol., in the press, 1960.

7) Hagiwara, S. AND Tasaki, I. A study on the mechanism of impulse transmission across the giant synapse of the squid. J. Physiol., 143: 114-137, 1958.

8) Tauc, L. Processus post-synaptiques d'excitation et d'inhibition dans le soma neuronique de 1'Aplysie et de 1'Escargot. Arch. Ital. Biol., 96: 78-110, 1958.

9) Yамамото, T. Animal Physiology. (in Japanese.) Tokyo, Kawade-shobo, 1949. 